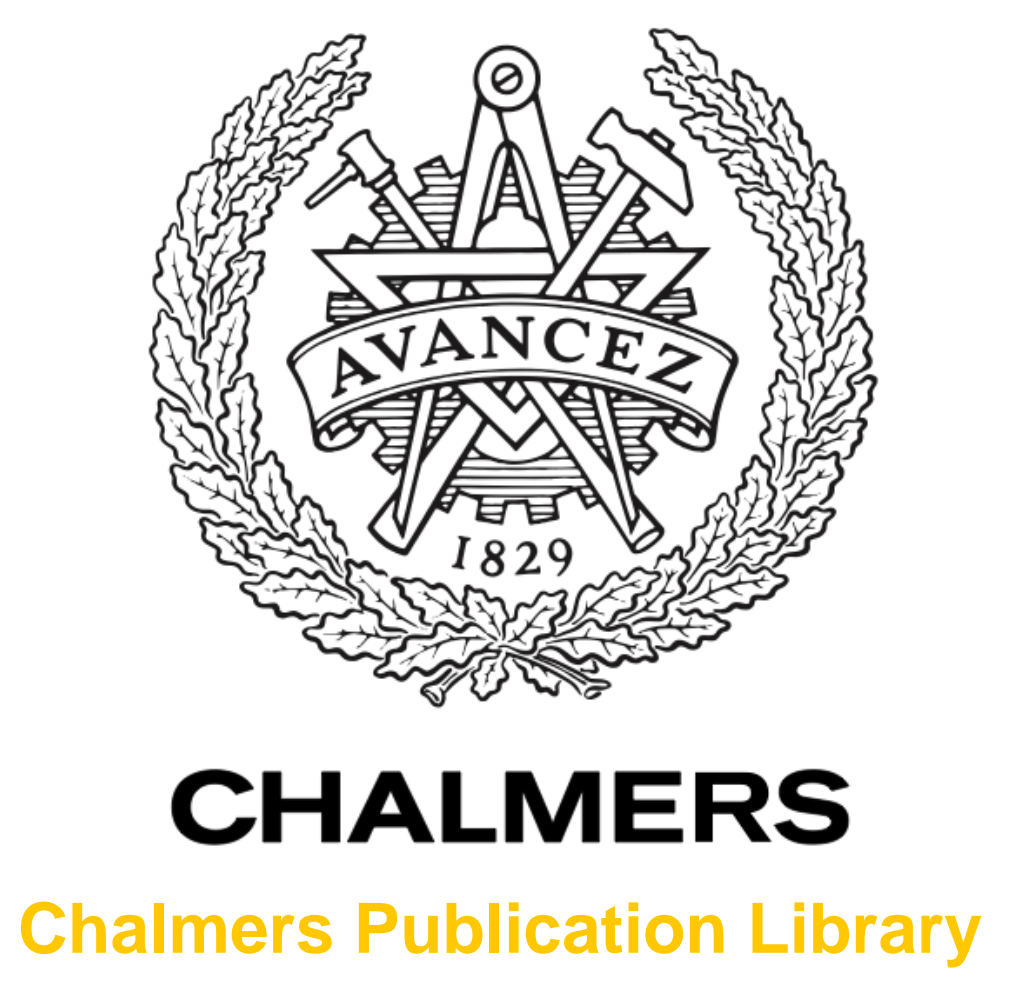

\title{
Some Aspects of An Analytical Framework for Studying the Diffusion of Organizational Innovations
}

This document has been downloaded from Chalmers Publication Library (CPL). It is the author's version of a work that was accepted for publication in:

Technology Analysis \& Strategic Management (ISSN: 0953-7325)

Citation for the published paper:

Alänge, S. ; Jacobsson, S. ; Jarnehammar, A. (1998) "Some Aspects of An Analytical

Framework for Studying the Diffusion of Organizational Innovations". Technology Analysis

\& Strategic Management, vol. 10(1), pp. 3-21.

Downloaded from: http://publications.lib.chalmers.se/publication/145720

Notice: Changes introduced as a result of publishing processes such as copy-editing and formatting may not be reflected in this document. For a definitive version of this work, please refer to the published source. Please note that access to the published version might require a subscription.

Chalmers Publication Library (CPL) offers the possibility of retrieving research publications produced at Chalmers University of Technology. It covers all types of publications: articles, dissertations, licentiate theses, masters theses, conference papers, reports etc. Since 2006 it is the official tool for Chalmers official publication statistics. To ensure that Chalmers research results are disseminated as widely as possible, an Open Access Policy has been adopted.

The CPL service is administrated and maintained by Chalmers Library. 
SOME ASPECTS OF AN ANALYTICAL FRAMEWORK FOR STUDYING THE DIFFUSION OF ORGANISATIONAL INNOVATIONS

Sverker Alänge

Staffan Jacobsson

Annika Jarnehammar

School of Technology Management and Economics

Chalmers University of Technology

S-412 96 Gothenburg, Sweden 


\begin{abstract}
The objective of this paper is to explore the extent to which the more recent literature on innovation and diffusion, with a prime focus on technical innovations, can contribute to a useful analytical framework for studying the diffusion of organisational innovations. We review that literature, compare the intrinsic features of technical and organisational innovations and explore what these differences may mean for an eventual analytical framework specifically developed for studying organisational innovations. We conclude that the received 'innovation' literature has a great deal to offer but that some modifications are required. In particular, we suggest that the role of factors 'inside' of the firm and of nonmarket mechanisms for transfer of organisational innovations need special emphasis.
\end{abstract}




\section{Introduction}

Any observer of industrial dynamics ${ }^{1}$ would be inclined to suggest that organisational innovations ${ }^{2}{ }^{3}$ have a profound impact on productivity and competitive advantage, user-supplier relations, the content of work etc. However, it still appears as if there is little systematic knowledge available about the determinants of the diffusion of organisational innovations and, indeed, about their effects. ${ }^{4}$ Edquist underlines this weakness:

'In this field our knowledge is much more scattered and the field is characterized by conceptual vagueness and unclarity...we have very little systematic empirical knowledge about the creation and diffusion of new organisational forms; it is a blank spot on the research map.' ${ }^{5}$

The purpose of this paper is to explore the extent to which the more recent literature on innovation and diffusion which focus on technical innovations ${ }^{6}$, can contribute to a useful analytical framework for studying the diffusion of organisational innovations.

The paper is, thus, exploratory and should be read in that way. It is set up as follows. Section two reviews some salient features of the innovation and diffusion process. We emphasize the local, cumulative and path-dependent nature of technological change. Section three compares technical and organisational innovations with respect to their intrinsic features and explore the implications these may have on the market for organisational innovations. The search and implementation processes of organisational and technical innovations are also contrasted. We find that although organisational and technical innovations share a set of characteristics, they also differ in some important respects. In particular, we suggest that the market for organisational innovations is relatively poorly functioning and that the local nature of the search process is even more accentuated. Section four discusses what implications these differences may have for analyzing the diffusion process of organisational innovations. We believe that much care has to be taken to define the object of study and that the 'inside' of the firm is particularly critical to understand when analysing the diffusion of organisational innovations. Moreover, we suggest that the transfer and implementation costs may be high and that the issue of standardization is central to the diffusion process. Finally, we argue that there are reasons to expect long diffusion periods and that non-market mechanisms for the transfer of organisational innovations are of considerable importance to the diffusion process. Section five pulls together the main conclusions. 


\section{The Nature of the Innovation and Diffusion Process}

The purpose of this section is to briefly review some of the more recent work on economics of innovation and diffusion. We will proceed by identifying a set of characteristics of the innovation and diffusion process.

\section{a) It is cumulative and path-dependent}

Technological change can be seen as a learning process which is mainly gradual and cumulative in character. ${ }^{7}$ A relatively ordered pattern of innovations can be observed along what Dosi labels technological trajectories. ${ }^{8}$ Learning and technological change at the level of the firm is also cumulative. Firms build upon their existing knowledge base and other assets when they search for new opportunities. As Dosi puts it:

'... the search process of industrial firms to improve their technology is not likely to be one where they survey the whole stock of knowledge before making their technical choices. Given its highly differentiated nature, firms will instead seek to improve and to diversify their technology by searching in zones that enable them to use and to build upon their existing technological base. In other words, technological and organisational changes in each firm are cumulative processes too. What the firm can hope to do technologically in the future is heavily constrained by what it has been capable of doing in the past'. ${ }^{9}$ (our emphasis)

Learning and technological change is therefore rooted in the present economic structure. In other words, it is path-dependent ${ }^{10}$ and largely ${ }^{11}$ local in nature.

Since learning is cumulative, the learning performance is presumably greatest when the object of learning is related to what is already known. This implies that it would be useful to understand how a new technology is related to the existing technology base. Granstrand \& Jacobsson ${ }^{12}$ suggest that the technological 'distance' could, in principle, be measured. For instance, intuitively, one would believe that the knowledge base of software design overlaps more with that of servo systems than with solid mechanics. ${ }^{13}$ 
b) The tacit nature of knowledge and the importance of networks ${ }^{14}$

Technological knowledge is to a varying degree tacit in nature. In each technology, there are elements which are tacit (person-embodied) and can therefore not be diffused easily. ${ }^{15}$ As this tacit component in the knowledge base increases, technological accumulation is more based on experience and communication and technology is increasingly transfered in a verbal fashion and through inter-personal contacts. ${ }^{16}$

Formal or informal networks are therefore important routes for the transfer of more tacit knowledge. ${ }^{17}$ These networks (including user-supplier relations and bridging institutions) are central to the innovation and diffusion. ${ }^{18}$ As emphasized by Lundvall and Johnsson, the learning process is therefore interactive where the institutional setup strongly affects the process of learning. ${ }^{19}$

Such interaction may, and does, take place over national borders and over large geographical distances but there are good reasons for suggesting that the interaction of firms belonging to the same nation might be the most efficient. ${ }^{20}$ As Lundvall argues in relation to the particular case of user-supplier links:

'When the technology is complex and ever changing, a short distance might be important for the competitiveness of both users and producers. Here, the information codes must be flexible and complex, a common cultural background might be important in order to establish tacit codes of conduct and to facilitate the decoding of the complex messages exchanged. The need for short distance will be reinforced when user needs are complex and ever changing.' ${ }^{21}$

On the other hand, it is well known that a network which reaches outside a dense core group, into more distant and less frequent contacts, can be of great importance for radical change, i.e. 'the strength of weak ties' in the words of Granovetter. ${ }^{22}$ This points in the direction that a firm needs a set of different contacts for each of the different aspects of the innovation ${ }^{23}$ and diffusion process. ${ }^{24}$

Moreover, all companies do not necessarily need to have direct contacts, as some actors in a network can function as information brokers or 'technological gatekeepers' for a local group. In this context, the importance of local meeting places for exchange of information has been emphasized ${ }^{25}$ and it has even been suggested ${ }^{26}$ that a dual network structure for technology diffusion may be appropriate, i.e. one local social network where at least one member also is a member of an international network. ${ }^{27}$ 
c) The relevance of technological systems or national systems of innovation

These networks, institutions and actors, form through their investment decisions highly specific national or regional technological contexts, or systems. ${ }^{28}$ These give rise to, and rest upon significant externalities ${ }^{29}$ which lie at the heart of the innovation and diffusion process.

These features of the innovation and diffusion process strongly suggest that the spatial context (nation, region) is not only still relevant in spite of trends towards internationalization but strongly influences the rate and direction of the search activities which lead to innovations, their subsequent evolution and diffusion.

Evidence of this is found in case studies (factory automation, electronics, material technology and pharmaceutical) of Sweden's technological systems. ${ }^{30}$ In a recent study of R\&D activities in the automobile industry a similar pattern was found. R,D \& $\mathrm{E}$ activities tend to take place near the home base. 'Only firms pursuing multi-regional strategies have partly dispersed $R, D \&$ E activities to major regional markets. ${ }^{31}$ More generalized findings are found in Patel $^{32}$ who analysed the geographical location of patenting activities (in the US) for 569 large firms and concluded that:

'...there is no systematic evidence... to suggest that widespread globalization of technological activities has occurred in the 1980's. The evidence... shows that for an overwhelming majority of them (firms) technology production remains close to the home base.' 33

d) Increasing returns as well as inertia ${ }^{34}$ characterizes the innovation process and national systems of innovation

Increasing returns apply to the process of innovation and initial specialization tends therefore to be reproduced and strengthened which results in different, uneven and divergent technological development amongst countries. ${ }^{35}$ This immediately raises important questions as to the capability of the innovation systems to improve their learning capability and, in particular, to adjust to new technical or organisational opportunities. Given increasing returns, there is a considerable risk that: 
* firms, institutions and networks become 'locked in' to the 'old technologies'. Thus, the cumulativeness and path-dependency of innovation may lead to a lock-in into technological, organisational and institutional cul-de-sacs. ${ }^{36}$

* the process of variety creation is hindered. In other words, there may be feedback mechanisms whereby a selection process may consume variety. ${ }^{37}$

* if a search for new technology or organisational forms is undertaken outside traditional areas, it is done in a highly localized fashion. Thus, the particular features of the firm's absorptive capacity ${ }^{38}$ influences its ability to evaluate new technical and organisation innovations and shapes its search process.

e) The innovation and diffusion process can not be distinguished in a meaningful way

Earlier work on diffusion, in terms of epidemic models ${ }^{39}$, emphasized that agents are imperfectly informed about a new technology and that a learning process, whereby partially tacit information is transmitted through observation and demonstration, takes place prior to adoption and diffusion. Such a learning process is, of course, interactive and therefore the particular characteristics, in terms of networks and institutions, of the local innovation or technological system matters for the rate of diffusion. ${ }^{40}$

However, whilst these models are obviously relevant, the gradual and cumulative nature of technical change makes it difficult and misleading to make a clear-cut distinction between innovation and diffusion. Indeed, a central feature of the diffusion process is how a new product, and the technology embodied in it, alters in the course of the diffusion process ${ }^{41} .^{42}$ It is therefore appropriate to see the diffusion curve as an envelope curve which is superimposed on a number of minor diffusion curves. ${ }^{43}$

\section{f) The influence from the supply side}

This alteration of the innovation may be a function of feedback from the market (learning-by-using, especially among technologically capable and demanding users), more resources devoted to $R \& D$ among the suppliers (which probably is function of prior diffusion ${ }^{44}$ ), increasing technological opportunities or changed strategic orientation among suppliers wishing to widen the market to segments hitherto unexploited but with a different demand characteristics. 
Some of these features have been incorporated into recent formal models of diffusion. Other diffusion models have begun to incorporate supply side factors. ${ }^{45}$ Although useful, they are quite limited in their perception as to which features of the supply side that matter.

Less formal analyses ${ }^{46}$ underline the importance that the strategic behaviour of the supplier industry has for a) changing the price/performance ratio of the new product, b) altering the product specifications to suit highly differentiated needs of various market segments, c) providing various types of services to reduce the percieved risk of adopters.

A local supplier industry, i.e. one located within a locationally bounded system, may have additional influences on the diffusion process by; d) diffusing information and knowledge about the new product through a locally relatively denser marketing network, and e) by giving local firms access to the new product in the early phases of the product's life when there may be limitations in the capacity or willingness of foreign suppliers to supply the product at a geographical distance. To the extent that the latter two factors are of importance, the strength of the local supplier industry in the technological system will have a bearing on the rate of diffusion.

In conclusion, the innovation and diffusion process is characterized by cumulativeness and path-dependency, where networks are conducive to the transfer of tacit knowledge and highly localized technological and innovation systems shape the search processes. The special features of the local technological systems greatly influence the diffusion process and the diffusion process can not be clearly distinguished from the innovation process. The strength of the local supplying industry and the character of the networks are particularly important features of the technological systems. 


\section{Some Differences and Similarities Between Technical and Organisational Innovations}

Having reviewed some salient characteristics of the innovation and diffusion process of technical innovations, we will proceed with comparing some features of technical and organisational innovations. We will structure the discussion in terms of a) differences which are intrinsic and how these affect the market for organisational innovations and b) differences in the search and implementation processes. First, however, a word of caution. The term organisational innovations covers a wide spectrum of innovations; for example, it can mean innovations in management practices, innovations in the administrative processes or innovations in the formal organisational structure. For analytical reasons, it would have been useful to have a taxonomy of organisational innovations but since we have not come across one in the literature, the discussion below (just as the one in section 2) will have to be carried out as if organisational innovations constitute a homogeneous entity. ${ }^{47}$

a) Intrinsic characteristics of organisational innovations and effects on the market for organisational innovations

Adopting an organisational innovation represents investment in knowledge, procedures, behaviour and relations rather than in artifacts. There are some intrinsic characteristics of such investments which we would expect to have a significant impact on the innovation and diffusion process in that they have a bearing on the particular features of the 'market' for organisational innovations.

First, organisational innovations are characterized by knowledge bases which are of a more tacit nature than for technical innovations. Whilst technical innovations have a large portion of hardware-embodied as well as a blue-print captured knowledge, the person-embodied knowledge for organisational innovations can only be supplemented by written rules, instructions, flow diagrams and organisational charts.

The tacit nature of the knowledge base of organisational innovations makes it difficult to protect these by patent; that is, imitation is not prevented by legal barriers, which creates ownership problems and, possibly, a lack of incentive to spend resources on developing organisational innovations ${ }^{48}{ }^{49}$ This lack of incentive, as compared to developing product innovations, can be compounded by the difficulties in selling organisational innovations on a market, thereby reducing the potential returns on any investment to develop the knowledge base for organisational innovations. ${ }^{50}$ 
Second, organisational innovations differ in that the supplier industry, in traditional meaning, is non-existent. Consultancy firms may be regarded as some kind of suppliers of organisational innovation, where their products consist of a standardised concept, which they try to sell and to implement. These firms, however, have a limited and difficult role to play due to both the tacit nature of knowledge and to particular features of the implementation process, discussed below. Organisational innovations, therefore, to a large degree, lack the very important determinant of the pattern and speed of diffusion which the supplier industry constitutes as regards technical innovations. ${ }^{51}$

Third, an organisational innovation refers to the creation of knowledge and, therefore, the marginal cost of 'production' and selling is equal to the reproduction and transfer costs. ${ }^{52}$ Whilst marginal costs are clearly not zero ${ }^{53}$ it is expected that the discrepency between marginal costs and fixed costs to develop the knowledge is substantial. To the extent that there is a market for organisational innovations, this would lead to problems of pricing, where price is clearly expected to be far above marginal costs.

Fourth, in addition to the tacitness of knowledge, organisational innovations are more difficult to observe, to define, and identify system borders for, than for technical innovations. These features of organisational innovations make it problematic to speak of a 'product' to be sold and bought on a market.

Finally, the costs and benefits of the 'product', the organisational innovation, are hard to evaluate for the potential adopter since trialability and observability could be assumed to be lower for organisational innovations than for technical innovations. It is, therefore, according to Kimberley, 'difficult to determine, in advance, the direct effects of managerial innovations on organisational performance $e^{54}$, i.e. it is difficult to find the ex ante criterion of 'profitability' for organisational innovations.

In conclusion, the incentives to develop organisational innovations are relatively poor. Consultancy firms can probably not fill the same role as, for example, machinery suppliers and there may be pricing problems in the diffusion process. Moreover, the product is difficult to define and it is hard to evaluate its costs and benefits. 


\section{b) The search and implementation process}

The features of the 'market' for organisational innovations suggest that it may not work very well and that, therefore, the characteristics of the local search process may be more important for organisational innovations than for technical innovations, i.e. the search process and its conditioning factors are extremely important. Some features of this process are listed below.

First, in contrast to technical innovations, organisational innovations do not normally have a specialized unit for development and diffusion, analogous to the R\&D or production engineering functions. ${ }^{55}$ This may suggest that the search for new and improved solutions is not always done in such a conscious and systematic way and not even towards explicitly stated goals.

Second, while top management can serve an important function in the adoption decision for technical innovations, in the case where there are explicitly stated goals for organisational change, the importance of top management involvement and visible support in order to implement organisational innovations is of another magnitude, as has been emphasized by most scholars. ${ }^{56}$

Organisational innovations concern humans, their behaviour and attitudes, relations and work tasks. It has been found that subordinates to a very large extent 'read' the behaviour of their managers in finding out what is really important, i.e. it is what the top manager does and visibly shows that gets most focus, not merely what he says. ${ }^{57}$

Third, organisational innovations often affect a larger number of individuals than most technical innovations. This means that a greater number of people or sub units within an organisation must support, or at least not openly resist, an organisational innovation before it is adopted ${ }^{58} .{ }^{59}$ Moreover, as pointed out by Teece, a major organisational innovation typically involves organisational disruption in that is associated with a major reassignment of tasks. ${ }^{60}$ Taken jointly, this may mean that organisational innovations meet greater internal challenge than technical innovations. ${ }^{61}$

Fourth, due to the difficulties in defining the 'product', organisational innovations can be shaped by the subjective interpretations of the adopter. ${ }^{62}$ The initial interpretation and the shaping of it to local contexts is, however, not usually done by all the affected people. Different categories of actors meet the innovation at different times and can 
therefore influence the precise character of the organisational innovation to different degrees. One assumption is that the early adopters within a firm have the largest influence and to some extent 'standardise' the shape for continued internal diffusion. ${ }^{63}$ However, in spite of this initial standardisation, organisational innovations can, to a larger extent than technical innovations, be assumed to gradually change while diffusing within a firm.

Fifth, the complementarity of technical and organisational innovations has been emphasized by several scholars. ${ }^{64}$

'The range of managerial options for achieving successful technology transfer includes changes in the user environment as well as in the technology itself and frequently the same misalignments can be addressed either way.' ...'A major proposition implied by this framework is that change in both technology and user environment is more beneficial than holding one constant and changing the other. ${ }^{65}$

This way of looking at change and adoption as an issue of obtaining a balanced approach. ${ }^{66}$ In a similar way, studies of organisational change, developed from an organisational development perspective, have emphasized the need to consider simultaneously not only technical and social systems, but also political and cultural systems $^{67} \cdot{ }^{68}$

In conclusion, whilst organisational innovations and technical innovations share the feature of mutual dependency, organisational innovations differ distinctly from technical innovations in that:

* the market is expected to work relatively poorly due to features on both the demand side (difficulties in defining and evaluating the 'product') and supply side (pricing, incentives and appropriability problems, lack of a supplier industry);

* the importance of the local characteristics of the search process is presumably more accentuated and;

* this search process is much determined by factors which are expected to vary greatly between firms (degree of conscious search, degree of local top management involvement, degree of internal challenge, the process of shaping and diffusing the innovation internally in the firm). 


\section{Implications for Analysing the Diffusion of Organisational Innovations}

These features of the 'market' and the search and implementation process of organisational innovations have important implications for their innovation and diffusion process. Not only is it difficult to know what to search for and what to implement but the features of the 'market' for organisational innovations mean that a whole set of issues arises: Which modes of transfer can be used to compensate for a poorly developed supply side; what is the role of networks in the diffusion of this highly tacit knowledge; what is the cost of non-market mediated transfer and what determines it? Moreover, the particular features of the search and implementation process suggest that a set of issues related to inertia, the cumulativeness of innovation and path-dependency appear highly relevant. These issues will be discussed in some detail in this section, beginning with the question of what the 'animal' really is.

\section{a) What is the animal and when is it adopted?}

As mentioned above, it appears to be more difficult to observe, define and identify system borders for organisational innovations than for technical innovations. Along with the subjective interpretation of an organisational innovation and the shaping of it in the intrafirm diffusion process, these features makes it difficult to specify what the innovation really is. What system borders does it have, is it the first trial version, or is it a later form, which most probably contains elements of further invention? Moreover, when should a organisational innovation be considered adopted by a firm? Is it the first time, e.g. when a new incentive system is being used on an experimental basis within a limited part of the organisation, or is it when the organisational innovation has a wider range of application within the organisation, possibly after being modified as a result of the first trial implementation? ${ }^{69}$

b) The importance of the 'inside' of the firm, inertia, user competence ${ }^{70}$ and unlearning

An extensive intrafirm diffusion is, of course, a precondition for observing any effects on the firm level. Since, the framework presented earlier, based on literature primarily within the field of economics of innovation and diffusion, focuses on interfirm diffusion, there is a need of a supplementary framework in order to analyse the diffusion processes inside firms. Intrafirm diffusion is the focus for literature dealing 
with implementation of innovations. ${ }^{71}$ This line of literature is to a large extent normative, case-based and often written by practitioners. ${ }^{72}$ Another theoretical/practical approach is represented by the literature on change in general, where scholars within the organisational development school have a prominent position. ${ }^{73}$ Due to a whole set of factors (e.g. the high degree of alterations in the diffusion process and the involvement of top management, etc.), this focus on the 'inside' of the organisation may be even more essential when it concerns organisational innovations than technical innovations.

As organisational innovations refer to relations between people, relations which are a function of institutions, we could expect there to be a considerable organisational inertia. Such an inertia could well be argued to be strengthened by the often significant 'set-up' costs and organisational disruption that follow upon an organisational innovation. ${ }^{74}$ The difficulties in experimenting with, usually indivisible, new organisational innovations would also tend to reinforce the cumulative character of organisational innovations. In other words, new organisational forms grow out of the old ones ${ }^{75}$ and the adoption of a specific innovation is influenced by earlier innovations that have been adopted or rejected. In principle, the diffusion of a particular innovation can be affected by parallel $^{76}$, sequential ${ }^{77}$, or synergistic $^{78}$ innovations. $^{79}$

As was discussed in section 2, inertia is a feature of the innovation and diffusion process of technical innovations but the subjective interpretation of organisational innovations, their malleability to prevailing organisational forms, and the close link between organisational innovations and the larger cultural and social context, may mean that this inertia is even greater in the case of technical innovations. Thus, pathdependency, the tendency to lock-in to a particular organisational path, is probably even stronger for organisational innovations than for technical innovations.

Inertia can also be expected to be found at the national level where a whole set of institutions may shape a path-dependent process of organisational development. An example is the Swedish (and Nordic) work organisation which since the 1960s has emphasized group-oriented, democratic and participatory models. The role of institutions in this process can be illustrated by how the focus of 'democratization' shifted from the firm to the bargaining table of the union and management at the central level coupled to new legislation (MBL) developed in the 1970s. At the same time, new institutions, such as 'Arbetslivscentrum' (Swedish Centre for Working Life) were created to support the orientation of the national system of innovation towards 
the use of these models. ${ }^{80}$ Hence, as for technical innovations, the process of pathdependency goes much beyond the individual firms.

To be able to break this path-dependency, companies need to 'unlearn', i.e. to abandon earlier practices and behaviours which were found useful and beneficial during an earlier stage. Kimberley points out that:

'.. almost nothing has been done on exnovation - the removal of an innovation from an organisation. Exnovation occurs when an organisation divests itself of an innovation in which it had previously invested. In some cases, exnovation may be different from what Zaltman et al. (1973) called discontinued use.' He continues: 'All managerial innovations are not right for all organisations at the same point in time. At any given time, organisations are in different stages in their life cycles (Kimberley, 1976a)...' and 'To be effective, managerial innovation must be implemented and used. Organisations must know when to dispose of innovations previously adopted as well as when to adopt new ones .' ${ }^{81}$

The ability to 'unlearn', break away from the old way of doing things, is among other things, dependent on the competence of the users. However, as distinct from technical innovations, the users are part and parcel of what is required to change. This may well mean that it is more difficult to articulate a demand for organisational innovations which depart from the prevailing ones. 'Technological distance', discussed in section 2, may therefore have an analogue 'organisational distance'. ${ }^{82}$ It can be hypothesized (and should be tested) that the more distant the new way of working is from the present way of working, the greater the resistance and the longer it takes before the decision is made to adopt the innovation. ${ }^{83}$

c) The cost of transfer and implementation of organisational innovations

Whilst the marginal costs for the supplier refers to the reproduction and selling costs, the cost for the user lies in the transfer and implementation costs. As mentioned above, these costs are usually significant ${ }^{84}$, which may affect both the pace and the pattern of diffusion. The high costs may occur for several reasons.

First, although there is no patent protection against imitation, the poor observability and the tacitness of the knowledge makes it difficult and costly to imitate an organisational innovation. Second, and as was mentioned above, there may be high 
costs in terms of organisational disruption. Third, organisational innovation may need to be adjusted to a greater extent than technical innovations to the specific circumstances of each firm ${ }^{85}$ which would suggest additional transfer costs. Indeed, there are similarities to the technical innovations' envelope curve (cf chapter 2) in that the product is not homogenous throughout its diffusion process. However, for organisational innovations, the diffusion curve may include a relatively large number of firm specific variants. Fourth, at times it may even be that the organisational innovation is overly wedded to the present organisational solution of each new adopter. This may arise as a consequence of the necessarily subjective interpretation of an organisational innovation, the fact that it refers to the relations between people and the large number of groups which may influence the particular features of an organisational innovation when it is implemented. This may not only be counterproductive, in the sense that the advantages of the organisational innovation may be lost when it is adjusted to the particular 'path' of the firm, but it may also be connected with unnecessarily high transfer costs.

In order to reduce the transfer and implementation costs, it may be important to try to standardise the organisational innovation's content and implementation as far as possible. In addition, the possibility of 'standardising' an organisational innovation can be assumed to influence the possibilities of seeing a major national impact from the organisational innovation. An example of this is the 'standardisation' done in Japan by The Union of Japanese Scientists and Engineers (JUSE), who designed a set of problem-solving tools most useful for the shop floor level (7 QC-tools) and another set of tools for engineers in Japanese industry (7 management tools) to be useful for the majority of the situations that an engineer encounters. In a similar way JUSE has tried to 'standardise' the characteristics of Japanese Total Quality Control (TQC), which can be seen as a major organisational innovation or maybe composed by several sub-innovations. ${ }^{86}$ The Malcolm Baldrige National Quality Award, The European Quality Award and The Swedish Quality Award show some similarity in their way of providing check-lists, but they do not try to standardise to the same extent.

In similar way implementation can be 'standardised' in order to facilitate and increase the success-rate. The practices of many consultancy firms is based on the assumption that it is possible to develop one way that suit most, although not all, companies. For consultancy firms this is in itself a driver, as the potential for profit is greatly increased if certain practices to a large extent can be repeated over and over again, given that other things, such as price, are equal. This way of thinking is essentially 
'industrial' and has a direct parallel in technical innovation, where the choice of a new product idea is made on the basis that the product is general, in that it suits the needs of many potential customers. ${ }^{87}$

In Japan once again, the implementation and diffusion of QC-tools, QC-circle activities, etc. have been 'standardised' in order to reach a maximum number of firms in the society with a proven solution that works well in most cases (and avoiding excessive adaptation at each firm). This is also one reason why the diffusion rate of the organisational innovation TQC has been quite high, regardless of the difficulty of estimating the economic effects of organisational innovations in general.

\section{d) The length of the diffusion process and modes of transfer of organisational innovations}

For a whole set of reasons (high set-up costs in terms of organisational disruption, difficulties in estimating the performance of organisational innovations, inertia among potential adopters, etc.), we would expect a tendency among potential adopters to delay any decision and in extreme cases act only when there is a severe profit crisis $^{88}{ }^{89}$ In the case of the automobile industry, Womack et al. made the following comment: 'In the absence of a crisis threatening the very survival of the company, only limited progress seems to be possible'. ${ }^{90} 9192$

On the other hand, this delay in adoption, which frequently occurs when organisational innovations are concerned, can give firms an opportunity to create a competitive advantage over a lengthy diffusion period. The firms who can benefit are early and aggressive adopters ${ }^{93}$ who have a superior organisational competence. ${ }^{94}$ Because of the poor functioning of the market in promoting the diffusion of organisational innovations, other mechanisms for diffusing organisational innovations must, therefore, be identified and analyzed. ${ }^{95}$

As underlined above, the costs and benefits of organisational innovations are hard to evaluate since trialability and observability could be assumed to be low and there is no analogus criterion to 'profitability' as for technical innovations. Hence, other criteria will be used in making decisions to adopt organisational innovations. One criterion that has been put forward is that firms tend to imitate other influential firms that can be seen as role models. 
'One criterion is the status of other organisations previously adopting'..., i.e. ...'imitation is likely to play a more significant role in the diffusion and adoption of organisational innovation than of technological innovation.' 96

As was discussed earlier, imitation takes place through a process of interactive learning whereby partially tacit information is diffused through networks and with the help of institutions. There are, therefore, good reasons to focus on the features of these systems of innovation when explaining the process of diffusion of organisational innovations.

The poorly functioning market for organisational innovations suggests that networks can have an even more central function to play in the diffusion of organisational innovations as compared to technical innovations. Through the network, the firm has access to communication channels, both formal and informal, where it can find social legitimacy, technical support and draw upon the experience of other members. This will reduce uncertainty and risks, both perceived and actual. The network may also provide slack resources, which can be used in the case of unexpected problems in the implementation process.

Networks can, however, both strengthen or weaken the process of unlearning and diffusion of a new organisational form. Some aspects of a network seem particularly important. The size of it may matter. With a larger network, the information passing through may not only be larger but also more diversified. As was mentioned in section 2, it is probably important to belong to dual networks in order to reduce the risks of being locked-in to a particular organisational path. ${ }^{97}$ The amount of slack resources may also be affected by the scale of the network. For these reasons, access to a larger and more diversified network(s) may facilitate adoption and speed up diffusion. Moreover, compatibility of network participants and the maturity of the network would also be expected to favour diffusion of state of the art organisational innovations. ${ }^{98}$

On the other hand, geographical dispersion can pose a major barrier to interfirm communication and a greater physical separation in a network will probably weaken the functioning of the network. In addition, a too heavy reliance on 'within network' information sources can stifle the diffusion of innovations by reducing the number of contacts that members have with information sources outside the network. 
Institutions matters too for the diffusion process. Returning to the Japanese example, the standardised implementation procedure of TQC was preceeded by many observable cases of earlier implementation within Japanese firms which could more easily be imitated through JUSEs standardised procedures (i.e. the diffusion followed an imitation pattern $)^{99}$. This removed the need to make separate economic calculation of the benefits of TQC for each company. Instead it is expressed as a 'belief' in Japan that the implementation of TQC will result in increased market share and profitability. ${ }^{100}$

JUSE substituted in this case for the absence of a supplier industry. Besides this kind of industry association, other mechanisms exists. For example, collective research institutes, such as the Swedish Institute of Production Engineering Research, as well as Universities, can be viewed both as bridging institutions in networks and as compensating mechanisms for the lack of a supplier industry. These institutions can, therefore, not only act as 'brokers' but also as educational institutes which transfer knowledge of organisational innovations to industry and services. ${ }^{101}$

A special case in the process of unlearning and diffusion of organisational innovations are the 'check-lists' for self-evaluation developed by collective research institutes and which are diffused by involving firms in a competition for Awards, e.g. Malcolm Baldrige National Quality Award in the USA, the Swedish Quality Award, or the European Quality Award. By following these check-lists (and eventually competing for the award), companies are strongly influenced to abandon earlier practices and adopt the principles of Total Quality Management. ${ }^{102}$

However, as a consequence of the tacit nature of the knowledge base of organisational innovations, the importance of 'unlearning', and the central role of top management involvement in change processes, we would expect there to be a limit to the degree to which such institutions can act as diffusion mechanisms. The transfer of key-people within firms, e.g. MNCs, and between firms, is probably therefore another key diffusion mechanism. ${ }^{103} 104$ 


\section{Conclusions}

We started out this essay in asking ourselves what the more recent literature on technical innovation and diffusion can contribute to shaping an analytical framework for studying the diffusion of organisational innovations. A first answer is that it probably has a great deal to contribute. The whole set of issues related to the cumulative nature of innovation, inertia and path-dependency appears to be highly relevant to organisational innovations. This refers to both the internal characteristics of the search and implementation process in firms, which is clearly of great importance, and to the wider context of networks, institutions and national systems of innovation geared towards particular trajectories. One of these issues refers to the difficulties encountered when trying to separate the innovation and diffusion processes. This is presumably even more accentuated for organisational innovations than for technical innovations. The role of national systems of innovation in finding non-market mediated transfer of organisational innovations would also seem to be of central importance due to the particular characteristics of the 'market' for organisational innovations. Institutions and networks, therefore, presumably matter greatly in the diffusion process of these innovations.

Thus, we can draw a number of interesting implications for an eventual analytical framework for studying the diffusion of organisational innovations.

First, the evasive nature of organisational innovations suggest that the definition of the object of the study need to be given special attention:

* where is the system boundary, what should be included in a specific organisational innovation?

* how should the temporal aspect of the innovation be handled, i.e. the process of continuous adaptation and change? The organisational innovation that reaches a firm's boundaries is usually not the same after some time, because of continued innovative or adaptive activities.

* when should an organisational innovation be considered to be adopted? Is it the first time management make a decision to use the innovation, or is it when it is implemented to a certain degree inside the adopting firm, and if so, to what extent? 
Second, assuming that:

* user competence is critical for the diffusion process;

* that 'unlearning' is central to the diffusion process;

* inertia, the cumulative nature of the innovation process may be even more accentuated for organisational innovations; and

* organisational innovations are to a large degree tacit and need to have firm-specific adjustment,

then, the experience base of the firm for handling organisational innovations is central to understanding the diffusion process. Thus, factors shaping the learning process within firms ought to be a central for studying the diffusion of organisational innovations. In other words, the absorptive capacity of firms, and what shapes the nature of it, needs to be understood. In this context, the concept of 'organisational distance' may be elaborated on and measured.

Third, given the special features of the 'market' for organisational innovations, we would expect that the market functions poorly and that, therefore, other modes of transfer have to compensate for that weakness. One of these compensating mechanisms is the position of the firms in various networks. Another is institutions such as industry associations and universities. Finally, the movement of tacit knowledge embodied in top-level management between and within firms presumably matters greatly. How well these compensating mechanisms work is presumably a key determining factor of the rate of diffusion in a given economy.

Fourth, to reduce the transfer and implementation costs, a certain degree of standardisation, of both the innovation itself and of its implemention, may be required. It seems essential to study these processes of standardisation.

Fifth, there is a need to look at diffusion of innovations in a wider context. It includes interdependencies of innovations, in relations that can be sequential, complementary, as well as directly or indirectly competing. It also includes cumulativeness and pathdependency, as well as factors influencing unlearning on national levels. 


\section{Acknowledgement}

We would like to acknowledge the financial support from the Swedish Institute for Quality (SIQ) and the Swedish Council for Work Life Research.

An early version of this paper was presented at the conference on 'Technological and Industrial Development', arranged by Chalmers University of Technology, Stockholm School of Economics and NUTEK. We are grateful to the participants in our session, in particular Charles Edquist, for comments. We are also grateful to the doctoral students in Work Organisation at the School of Technology Management and Economics, Chalmers University of Technology, for a very fruitful discussion in another seminar. Howard Rush and John Bessant gave valuable comments on a subsequent draft.

\section{Notes and References}

\footnotetext{
${ }^{1}$ See B. Carlsson, 'Reflections on Industrial Dynamics', International Journal of Industrial Organisation, 5, 1987, pp.135-148, for deliniation of the field of enquiry which he labels Industrial Dynamics.

${ }^{2}$ F. Damanpour, K. A. Szabat \& W. M. Evan, 'The relationship between types of innovation and organisational performance', Journal of Management Studies, Vol.26, No.6, pp.587-601, 1989, and E. Rogers, Diffusion of Innovations 3rd ed., (New York, The Free Press, 1983).

${ }^{3}$ Innovation is here defined according to Rogers (1983) as 'any idea, object, or practice that is perceived as new by the members of the social system', i.e. the innovation is viewed from the perspective of the customer and not that of the producer. In addition, in this paper the concepts of organisational, administrative and managerial innovation are used interchangeably. Administrative innovations are sometimes seen as encompassing both organisational change and change in management system (Damanpour et al. 1989), while others use the concept organisational innovation in the same wide sense. In the present paper, the three concepts are used interchangeably.

${ }^{4}$ D. Teece (1981, p: 173, cited in Edquist 1992) argues that 'Business historians have long been aware that organisational innovations have had remarkable productivity ramifications. A.H. Cole has asserted that "if changes in business procedures and practices were patentable, the contributions of business change to the economic growth of the nation would be as widely recognised as the influence of mechanical innovations".'

${ }^{5}$ C. Edquist , 'Technological and Organisational Innovations, Productivity and Employment', World Employment Programme Research Working Paper, WEP 2-22/WP.233, 1992.

${ }^{6}$ P.A. David, 'Path-Dependency: Putting the Past into the Future', Stanford University, Institute for Mathematical Studies in the Social Sciences, Economic Series, Technical Report No 553, November, 1988, and G. Dosi, 'Sources, Procedures and Microeconomic Effects of Innovation', Journal of Economic Literature, Vol. XXVI (September), 1988, pp.1120-1171, and G. Dosi, K. Pavitt \& L. Soete, The Economics of Technical Change and International Trade, (Harvester/Wheatsheaf, 1990), and G. Dosi, D. Teece \& S. Winter, 'Toward a theory of corporate coherence', in: G. Dosi, R. Giannetti, P.A. Toninelli (Eds), Technology and the Enterprise in a Historical Perspective (Oxford, Oxford University Press,1991), and B.Å. Lundvall (Ed), National Systems of Innovation. Towards a Theory of Innovation and Interactive Learning, (London, Francis Pinter, 1992), and S. Metcalfe, 'The Economic Foundations of Technology Policy: Equilibrium and Evolutionary Perspectives', mimeo, (University of Manchester, 1992), and P. Patel \& K. Pavitt, 'Uneven (and divergent) technological development amongst countries and firms: evidence and explanations', mimeo, (Science Policy Research Unit, University of Sussex, U.K, 1993).

${ }^{7}$ Lundvall 1992, op. cit., Ref. 5.

${ }^{8}$ Dosi 1988, op. cit., Ref.5.

${ }^{9}$ G. Dosi, 'The nature of the innovative process', in: G. Dosi, C. Freeman, R. Nelson, G. Silverberg, \& L. Soete (Eds), Technical Change and Economic Theory (London, Francis Pinter, 1988), p. 225
} 
${ }^{10}$ David 1988 and Dosi et al. 1991, op. cit., Ref.6

${ }^{11}$ This may be less so for radical technical change than for incremental change. Many times though, it appears as if technological discontinuities build upon, and expand a firm's existing technology base rather than replacing it (see e.g. O. Granstrand \& S. Jacobsson, 'When are Technological Changes Distruptive? - A Preliminary Analysis of Intervening Variables Between Technological and Economic Changes', Paper presented at the Marstrand Symposium on Economics of Technology, (Marstrand, Sweden, August, 1991), and P. Patel \& K. Pavitt, 'The continuing, widespread (and neglected) importance of improvements in mechanical technologies', mimeo, (Science Policy Research Unit, University of Sussex, U.K, 1993), and C. Oscarsson, Technology diversification the phenomenon, its causes and effects, Doctoral dissertation, (Department of Industrial Management and Economics, Chalmers University of Technology, Gothenburg, Sweden, 1993).

${ }^{12}$ Granstrand \& Jacobsson 1991, op. cit., Ref.11

${ }^{13}$ In a corresponding way, the concept of 'technological families' introduced by Gustafsson (1981) is based on the rationale that there are product groups which share a common technology base, and that the learning processes are facilitated if they occur in related production technologies. (see H. Gustavsson, 'On-the-Job Learning and Resource Allocation in Developing Countries: A measurement problem in project appraisal and a proposal to its solution', Master Thesis, (University of Sussex, UK, 1981).

${ }^{14}$ A network is here defined as actors, e.g. firms, organisations, associations, or individuals engaged in the production, distribution, or use of goods, services, and knowledge. In these networks, information is spread via personal contacts, either formally or informally.

${ }^{15}$ Dosi 1988 and Metcalfe 1992, op. cit., Ref. 6, and D.S. Landes, Inaugural lecture at the E.A.R.I.E. 18th Annual Conference, (Ferrara, Italy, September 1-3, 1991).

${ }^{16}$ Metcalfe 1992, op. cit., Ref. 6

${ }^{17}$ ibid. and E. Rogers, 'The Rise of Silicon Valley', mimeo, (Institute for Communication Research, Stanford University, 1981).

${ }^{18}$ E. von Hippel, The Sources of Innovation, (New York, Oxford University Press, 1988, and B. Carlsson \& S. Jacobsson, 'Technological Systems and Economic Policy: The Diffusion of Factory Automation in Sweden', Research Policy, forthcoming, 1993.

${ }^{19}$ B.Å. Lundvall, 'Introduction', in Lundvall, (Ed), (1992), op. cit., Ref. 5, and B. Johnsson, 'Institutional Learning', in Lundvall, (Ed), (1992), op. cit., Ref. 5.

${ }^{20}$ Information technology may to some extent reduce the negative effect of geographical distance (Daniels \& Daniels 1993, and Davenport 1993), but there are limitations in terms of transferring information of a more tacit nature. (See J. L. Daniels \& N. C. Daniels, Global Vision - Building New Models for the Corporation of the Future, (New York, McGraw-Hill, 1993), and T. H. Davenport, Process Innovation - Reengineering Work through Information Technology, (Boston, Harvard Business School Press, 1993).

${ }^{21}$ B. A. Lundvall, 'Innovation as an interactive process; from user-supplier interaction to the national system of innovation', in Dosi, G; Freeman, C; Nelson, R, Silverberg, G and Soete, L (Eds), Technical Change and Economic Theory, (London, Francis Pinter, 1988, p.355).

${ }^{22}$ M. S. Granovetter, 'The Strength of Weak Ties', American Journal of Sociology, No.78, 1973, pp.1360-1380.

${ }^{23}$ For the R\&D process it is known that an R\&D team needs different kind of contacts during different phases of the development process. During early phases, the team benefits from many and disperse contacts (including weak-ties), while during later phases, the successful teams mostly turn inward and limit the outside contacts to a vital few (See T. Allen, Managing the Flow of Technology, (Cambridge, MA, The MIT Press, 1984), and S. Sjölander, Innovation och Företagsförnyelse-Ideutveckling och Idehantering i Företag, (Malmö, Liber, 1983) in Swedish).

${ }^{24}$ Given a basic technical understanding and a common language of communication, one single contact to a capable machinery supplier, not necessarily in the vicinity, can provide a firm with the latest technology ahead of most international competitors, e.g. as was the case for a small Swedish company producing advanced technical textiles, which had very well established links to an advanced German machinery supplier (S. Alänge \& S.Jacobsson, 'Svensk Tekoindustris Infrastruktur', Report submitted to NUTEK, (NUTEK, Stockholm, 1992).

${ }^{25}$ cf. I. Frej, 'Grundläggande teknologier för småindustrietablering', Examensarbete, no. 1980-9 (Masters Thesis in Swedish), (Göteborg, Dept. of Industrial Management, Chalmers University of Technology, 1981), and E. M. Rogers \& D.L. Kincaid, Communication Networks - towards a new paradigm for research, (New York, The Free Press, 1981).

${ }^{26}$ G. Reitberger, 'Forskning om teknikspridning', Report submitted to the National Swedish Board for Technical Development (STU), (Stockholm, STU, 1984), and B. Johannisson, 'Business and Local Community - Swedish experiences from bottom-up planning for local industrial development', Report 1985:4, (Östersund, University of Östersund, 1985).

${ }^{27}$ International colloborative R\&D ventures have increasingly become a form of extended contacts (Mowery 1987) which indicates that even international network can be of a tight nature. (See D. Mowery, Alliance Politics and Economics - Multinational Joint Ventures in Commercial Aircraft, (Cambridge, MA, Ballinger, 1987). 
${ }^{28}$ B. Carlsson \& R. Stankiewicz, 'On the Nature, Function, and Composition of Technological Systems', Journal of Evolutionary Economics, 1 (2), 1991, pp.93-118, and Lundvall 1992, op. cit., Ref. 5, and R. Nelson (Ed.), National Innovation Systems; A Comparative Analysis, (Oxford University Press, 1993).

${ }^{29}$ Dosi et al. 1990, op. cit., Ref. 6, B. Carlsson \& S. Jacobsson, 'Technological Systems and Industrial Policy', in: C. Freeman \& D. Foray (Eds), Technology and Competitiveness. The Dynamics of Created Advantages, (Pinter Publishers, 1991), and Carlsson \& Jacobsson 1993, op. cit., Ref. 18.

${ }^{30}$ B. Carlsson, G. Eliasson, A. Granberg, S. Jacobsson \& R. Stankiewicz, 'Sveriges teknologiska system och framtida konkurrenskraft', report submitted to NUTEK, (Stockholm, NUTEK, 1992).

${ }^{31}$ Miller (1994) found that the process of large scale innovation, the acceleration of product development, and the increasing strategic importance of technology were factors contributing to the concentration of R, D \& E activities close to the home base. Factors limiting the concentration were the dispersion of foreign sales, the surveillance of competitors' engineering and styling activities, and the support of foreign assembly plants. Furthermore, the development of global networks is constrained by communication difficulties, travel time and cost, and by pressures for regional autonomy. (See R. Miller, 'Global R\&D networks and large-scale innovations: The case of the automobile industry', Research Policy, Vol.23, No.1, 1994, pp.27-46.

${ }^{32}$ P. Patel, 'Localized Production of Technology for Global Markets', mimeo, (University of Sussex, UK, Science Policy Research Unit, 1993).

${ }^{33}$ However, recent interview data suggest that firms who have a global marketing strategy including a wish to be perceived as a local entity on each market, to an increasing extent are also in the process of globalizing their R\&D, e.g. ABB, Honda, IBM, Motorola and NEC.

${ }^{34}$ Inertia is here defined as unwillingness to change or, if a change is implemented, to change in certain, already known, directions. On the level of the whole organisation, the company is usually said to be 'path-dependent'.

${ }^{35}$ Patel \& Pavitt 1993, op. cit., Ref. 6.

${ }^{36}$ W. Cohen \& D. Levinthal, 'Absorptive Capacity: A New Perspective on Learning and Innovation', Administrative Science Quarterly, 35, 1990, pp. 128-152, and Lundvall 1992, op. cit., Ref. 5, and B. Carlsson \& S. Jacobsson, 'Technological Systems and Development Potentials - a Policy Discussion', mimeo, (Department of Industrial Management and Economics, Chalmers University of Technology and Department of Economics, Case Western Reserve University, Cleveland, 1993).

${ }^{37}$ Metcalfe 1992, op. cit., Ref. 6.

${ }^{38}$ Cohen \& Levinthal 1990, op. cit., Ref. 36.

${ }^{39}$ see C. Thirtle \& V. Ruttan, The role of demand and supply in the generation and diffusion of technical change, (Harwood Academic Publishers, 1987).

${ }^{40}$ Carlsson \& Jacobsson 1993, op. cit., Ref. 18, and J. Bessant \& H. Rush, 'Building bridges for innovation; the role of consultants in technology transfer', Research Policy, 1994 (forthcoming).

${ }^{41}$ N. Rosenberg, Perspectives on Technology, (Cambridge University Press, 1976), and B. Gold, 'Technological diffusion in industry; research needs and shortcomings', The Journal of Industrial Economics, Vol. XXIX, no.3, 1981, pp. 247-269.

${ }^{42}$ The example of numerically controlled machine tools (NCMT) can illustrate this feature. Whilst the first NCMT was produced as early as in 1955, it took two major changes (and twenty years) in the underlying technology base and associated price/performance characteristics (and a whole range of minor improvements) before NCMTs began to be diffused on a large scale (S. Jacobsson, Electronics and industrial policy. The case of computer controlled lathes. World Industry Studies 5, (London, Allen \& Unwin, 1986), and E. Ehrnberg \& S. Jacobsson, 'Technological Discontinuity and Competitive Strategy -Revival through FMS for the European Machine Tool Industry?' In Technological Forecasting and Social Change, 1993).

${ }^{43}$ E. Ehrnberg \& S. Jacobsson, 'Technological Discontinuities, Industry Structure and Firm Strategy- The Case of Machine Tools and Flexible Manufacturing Systems', Department of Industrial Management and Economics, Chalmers University of Technology, Gothenburg, Sweden, 1991, and Metcalfe 1992, op. cit., Ref. 6.

${ }^{44}$ Metcalfe 1992, op. cit., Ref. 6.

${ }^{45}$ For a review, see Thirtle \& Ruttan 1987, op. cit., Ref. 39.

${ }^{46}$ Rosenberg 1976, op. cit., Ref. 41, Ehrnberg \& Jacobsson 1993, op. cit., Ref. 42, Carlsson \& Jacobsson 1991, op. cit., Ref. 29, Carlsson \& Jacobsson 1993, op. cit., Ref. 18.

${ }^{47}$ Edquist 1992, op. cit., Ref. 5, briefly discusses this issue and makes a distinction between organisational innovations with respect to their factor saving biasses and the degree to which they can be transferred between countries.

${ }^{48}$ D. Teece, 'The diffusion of an administrative innovation', Management Science, Vol. 26, No.5, May, 1980, pp. 464-470.

${ }^{49}$ On the other hand, tacit knowledge is easier to protect.

${ }^{50}$ As the importance of company specific organisational techniques are realized, we will probably still see an increasing priority given to developments of the firm's knowledge base in this field; investments which may have little to do with selling on the market.

${ }^{51}$ For an analysis of the role of consultants in technology transfer, see Bessant \& Rush 1994, op. cit., Ref. 40. 
52 Teece 1980, op. cit., Ref. 48.

${ }^{53}$ D. Teece, The Multinational Corporation and the Resource Cost of International Technology Transfer, (Cambridge, MA Ballinger, 1976).

${ }^{54}$ J. R. Kimberley, 'Managerial Innovation', in P. C. Nystroem \& W. H. Starbuck (Eds), Handbook of

Organisational Design, (New York, Oxford University Press, 1981, p: 87).

${ }_{55}$ There are companies that have developed a search and development function for organisational practices, e.g. units within the Motorola University.

${ }^{56}$ Cf. S. Alänge, 'Total Quality Management as a Tool for Organisational Change', CIM Working Paper, No. WP 1992-01, (Göteborg, Chalmers University of Technology, 1992), and P. Spenley, World Class Performance through Total Quality - A Practical Guide to Implementation, (London, Chapman \& Hall, 1992).

${ }^{57}$ The worst case of course being when a mixed message is provided, when there is no correspondence between what the boss says and what he/she does.

${ }^{58}$ Kimberley 1981, op. cit., Ref. 54.

${ }^{59}$ In large corporations it has been found that major organisational change programmes started by a central corporate office usually lead to failure. Instead, a success pattern has been found when an organisational innovation first is adopted, adapted and diffused by line management in a subunit, division etc., and then later on, when an internal success case exist, the innovation can be diffused and implemented on a wider scale within the corporation. (See M. Beer, R. A. Eisenstat, \& B. Spector, 'Why Change Programs Don't Produce Change', Harvard Business Review, November-December 1990, pp.158-166.

${ }^{60}$ Teece 1980, op. cit., Ref. 48.

${ }^{61}$ Empirical work is required to verify whether or not this is the case.

62 This subjective view is further reinforced by the consultancy firm's interest in packaging organisational innovations and making their offer unique. The result is that essentially the same innovation is described in different sets of 'proprietary' concepts. E.g. Western consultancy firms catching up on the experiences developed within Japanese industry (in Japan called TQC, CWQC or Toyota management system, etc) describe their own packaged offers in terms such as 'resourceful organisations', 'horizontal organisations', etc. What the consultancy firms add to the general concept and features of TQC is primarily their experience of analysing and implementing the concept in a larger number of firms. This experience contains a strong factor of learning for each time the innovation is implemented, which is culture specific depending on the nation/region and corporation in which the consultant has been active.

${ }^{63}$ This 'standardising' has been seen as a factor slowing the internal diffusion process (H. Hasselbladh, Administrativa innovationer i organisationer, (Uppsala, Department of Business Administration, University of Uppsala, 1991). On the other hand, the opposite view is probably more common and recommended in normative books, i.e. often the initial use of a pilot project which lays the foundation for a firm specific standardisation is prescribed.

${ }^{64}$ Cf. D. Leonard-Barton, 'Implementation as mutual adaptation of technology and organisation', Research Policy, 17, 1988, pp. 251-267, and Damanpour et al. 1989, op. cit., Ref. 2.

${ }^{65}$ Leonard-Barton 1988, op. cit., Ref. 64.

${ }^{66}$ E. Trist, 'The Evolution of Socio-Technical Systems', Occasional Paper, No.2, 1981, Ontario Quality of Work Life Centre, Toronto.

${ }^{67}$ N. Tichy, Managing Strategic Change - Technical, Political and Cultural Dynamics, (New York, John Wiley \& Sons, 1983), and Alänge 1992, op. cit., Ref. 56,

${ }^{68}$ Edquist 1992, op. cit., Ref. 5, emphasizes that the distinction between technological and organisational change is analytical in nature because it is extremely difficult to distinguish sharply between them in the real world, and the two concepts are often related to one another in an often complex way.

${ }^{69}$ A common definition of an innovation refers to the point in time when it is first used in production for a commercial market, and in a similar way the adoption of an organisational innovation can be tied to the first use for commercial production (H. Rush, 1994, personal communication). However, a limited production for a market during a pilot test phase, does not necessarily mean that the organisational innovation is in any regular use within the firm. Rather, it could be argued that the subsequent diffusion to other departments could be considered as the starting point for the adoption of the innovation.

${ }^{70}$ Here user competence refers to both the ability to search for new opportunities and the ability to implement and manage change. The ability to search for new opportunities means the ability to find, to interpret, to understand, and to choose, in this case, an organisational innovation. The ability to implement and manage change means the ability to make the employees understand the need for change in the organisation, to set goals in the right direction, to organise the change process, to involve, motivate and mobilize the work force in the right direction, and finally to measure and keep track of the goals.

${ }^{71}$ 'The literature on organisational innovation is vast and diverse. The studies focusing on invention, on the initial adoption decision or technology transfer among organisations are less relevant to understanding post adoption issues than is the research focused specifically on implementation.' (Leonard-Barton 1988, op. cit., Ref. 64). 
${ }^{72}$ E.g. Spenley 1992, op. cit., Ref. 56.

${ }^{73}$ E.g. R. Beckhart \& R. T. Harris, Organizational Transitions: Managing Complex Change, (Reading, MA, Addison-Wesley, 1977), and E. H. Schein, Organizational Culture and Leadership, (San Francisco, Jossey-Bass, 1980).

${ }^{74}$ Teece 1980, op. cit., Ref. 48.

${ }^{75}$ For instance, the Volvo Uddevalla plant grew out of the long experience of Volvo factory in Kalmar.

${ }^{76}$ Parallel innovations can either be directly competitive in such a way that they perform almost the same function or are directed towards the same area, or indirectly competitive in such a way that they compete for the same limited resources in terms of money, managerial capacity, etc.

${ }^{77}$ In the case of the sequential form of diffusion, where one innovation is perceived by the individuals in an organisation as a direct continuation of an earlier failure, major barriers are created. To overcome such barriers can be a matter of several years.

${ }^{78}$ Especially in the case of organisational and technical innovations there can be a direct synergistic condition. For example, the diffusion of new information technology in the form of distributed PC-based networks condition and positively enforce the diffusion of decentralized management practices in large corporations.

${ }^{79}$ Kimberley 1981, op. cit., Ref. 54.

${ }^{80}$ A. Berger, 'Några spridda tankar kring organisatoriska innovationers uppkomst, spridning och adoption', mimeo, Department of Industrial Management and Economics, Chalmers University of Technology, Göteborg, Sweden, 1993.

${ }^{81}$ G. D. R. Zaltman \& J. Holbek, Innovations and Organisations, (New York, John Wiley \& Sons, 1973), and J. R. Kimberley, 'Issues in the design of longitudinal organizational research', Sociological Methods and Research, No: 4, 1976a, pp: 321-347, and Kimberley 1981, op. cit., Ref. 54.

${ }^{82}$ Organisational distance is here defined as the distance between the old and the new way of working. That is, differences in working routines, organisation, ways of communication etc.

${ }^{83}$ On the other hand, because of the tacitness of organisational innovations it may well be that potential adopters cannot easily distinguish between organisational practices that are closer to each other, which either can result in the rejection of a new organisational innovation on the grounds that it already has been implemented, or the result can be the adoption of certain new concepts while no real change in practice take place.

${ }^{84}$ Teece 1980, op. cit., Ref. 48.

${ }^{85}$ ibid.

${ }^{86}$ This has been done through committee work on what constitutes the Japanese TQC (JUSE 1987) and it is being enforced through the requirements for the Deming Prize, which is the Japanese quality award given to the company that best fullfil the TQC requirements. (See JUSE, 'Features of Company-Wide Quality Control in Japan', by T. Ikezawa, Y. Kondo, A.Harada \& T. Yoneyama, Proceedings form the International Conference on Quality Control (ICQC) in Tokyo 1987, pp.43-47.

${ }^{87}$ Carlsson \& Jacobsson 1991, op. cit., Ref. 29.

${ }^{88}$ V. Mahajan, S. Sharma \& R. D. Bettis, 'The Adoption of the M-form Organisational Structure: A Test of Imitation Hypothesis', Management Science, Vol.34, No.10, 1988, pp. 1188-1201.

89 There are cases when adoption is done before a real profit crisis. Often then, a strong institutional structure exist or other external factors such as influential customers requiring a change, which for a small supplier firm can be perceived as close to a crisis. The adoption can also take place because of a 'bandwagon or demonstration effect' set in motion by leading companies (see e.g. K. Bemowiski, 'The Benchmarking Bandwagon', Quality Progress, January 1991.

${ }^{90}$ J. P. Womack, D. T. Jones \& D., 'The Machine that Changed the World, (New York, Macmillan Publishing Company, 1990).

${ }^{91}$ One point in case is the Swedish Saab Automobile plant, which after a severe crisis has rapidly adopted the principles of 'lean production' and incorporated Japanese managerial experiences and methods into its production plant in Trollhättan.

92 This may be one contributing factor to Kimberley's proposition that '..certain managerial innovations are likely to diffuse counter-cyclically.'.....As total income increases, consumption of technological innovations increases, whereas consumption of certain managerial innovations does not. As total income shrinks, however, consumption of these managerial innovations is likely to increase.' (Kimberley 1981, op. cit., Ref. 54, p.94)

93 Mahajan et al. 1988, op. cit., Ref. 88.

${ }^{94}$ For many reasons dealt with in this paper, firm specific knowledge in organisation can be more sustainable than technological knowledge.

95 Government policy may be conceived of as one corrective mechanism. For a review of some innovative technology transfer policies, see Bessant \& Rush 1994.

${ }^{96}$ Kimberley 1981, op. cit., Ref. 54. 
97 The dual network structure consists of a tight local network complemented by a weak-ties network out into a diversified world.

${ }^{98}$ M. M. McKinney, A. D. Kaluzny \& H. S. Zuckerman, 'Paths and Pacemakers; Innovation Diffusion Networks in Multihospital Systems and Alliances', Health Care Management Review, Vol. 16, 1991, pp. 17- 23.

${ }^{99}$ However, 'the imitation pattern' does not always seem to be the way that organisational innovations diffuse. In a meta-study of the diffusion of the M-form, i.e. a complex administrative innovation, Mahajan et al. (1988, op. cit., Ref. 88) found that '.. unlike the adoption of technological innovations, complex administrative innovations may not follow the imitation process'. Mahajan et al. provided three major reasons for this result: 'To sum, ... the uncertainty associated with the performance advantages of the M-form structure, the unique nature of the innovation itself and organisational momentum may be some of the reasons causing the adoption of the M-form structure not to follow the imitation process.' (our emphasis).

100 Shiba 1987, personal communication.

${ }^{101}$ In addition, the consultants (the 'supplier industry' of organisational innovations) sell a packaged product which undergoes a continuous learning cycle each time it is implemented in a new organisational setting.

102 One instrument on these lists is the use of systematic benchmarking techniques, i.e. to compare processes with best practice in industry in general, not only in the own industry, in order to avoid not-invented-here biases and increase the speed of the diffusion of organisational innovations.

${ }^{103}$ In Japan, this practice of transferring people and hence, their tacit knowledge, is well developed. One example is the practice of letting a development engineer follow the product downstream. Another example is the habit of moving people that are getting close to retirement age to a supplier firm (S. Alänge, O. Granstrand \& S. Sjölander, 'Some Preliminary Impressions from Japan', CIM Working paper, No. WP 1988-06.

${ }^{104}$ Political and legal constraints_can facilitate the diffusion process (Kimberley 1981, op. cit., Ref. 54). One clear example of this is the rapid diffusion of ISO 9000 certification in the UK, which mainly can be explained by the Thatcher government's decision to require all suppliers to the state to have a ISO 9000 certificate by a certain date. The result was that all firms considering involving themselves in government procurement activities rushed to get a certificate. Adoption of a new technology does not, of course, automatically lead to successful implementation. 